\title{
Study on the Design of Bed and Breakfast in Rise of Non - standard Accommodation Boom
}

\author{
Ren-zhi Tao; Ming Chen \\ School of Civil Engineering and Architecture, Wuhan University of Technology \\ Wuhan430070, China
}

\begin{abstract}
Starting from the development of domestic and foreign research, this paper finds out the common problems in the design and construction of the Chinese $B \& B$. By analyzing the typical cases of the excellent $B \& B$ projects, it puts forward the rational and distinctive policy and explores sustainable development of $B \& B$ in rise of non-standard accommodation boom in China.
\end{abstract}

Keywords—Non-standard accommodation; Accommodation; Case study; Design strategy

\section{INTRODUCTION}

In November 2015, the State Council issued the guiding document on the structure upgrading of the life service industry, which presented the active development of green hotels, themed hotels, guest houses, short rent apartments, long rent apartments, organic dining, fast food dinners, special restaurants, farmhouse and other segments to meet the demands of the mass consumers." Bed and Breakfast "for the first time in the national policy document was mentioned.

In recent years, China's rise of non-standard accommodation boom, as an important part of its accommodation, with the national policy to support efforts to increase the formation of a very broad market space. B \& B design not only need to integrate folk culture, cultural creativity, landscape and other resources, but also the designer's romantic feelings and rational thinking.

\section{THE DEVELOPMENT OF DOMESTIC AND FOREIGN B\&B}

At present, the academic community for "Bed and Breakfast" understanding is deepening. Some scholars have defined it as "the operator with local environment, humanities, construction resources, for consumers to create a family atmosphere with a small dining accommodation" [1]. For example, in the Lishui City issued "on the development of rural features $\mathrm{B} \& \mathrm{~B}$ to deepen the creation of farmhouse complex guidance", the hotel is defined as "the use of rural housing and courtyard operators, combined with regional natural landscape, ecological environment, Agriculture, forestry, animal husbandry and fishery production activities, to "slow life", "home service", "fun experience" for visitors to provide rural living space.

Non-standard accommodation, different from the standard hotel, by individual owners, housing tenants or commercial institutions for tourism, business travel and other housing needs of consumers in addition to bed, bathroom, more personalized facilities and services accommodation options, including the inn, $\mathrm{B} \& \mathrm{~B}$ and so on. Among them, $\mathrm{B} \& \mathrm{~B}$ is the most extensive and most popular [2].

In the early 1960 s, the UK's relatively sparsely populated remote areas appeared the first types of accommodation. As a result of life distress, farmers provided simple accommodation and food for traveling people to subsidize home, which belonged to home service.

In nineteen eighties, the $\mathrm{B} \& \mathrm{~B}$ rapidly developed, especially in Taiwan and Japan. At that time, because of the imperfections in the surrounding area, Taiwan residents could not provide adequate accommodation. The nearby residents rented vacant houses to tourists for their use. In the 1990s, Taiwan's agriculture fell under the impact of the international market, while the leisure agriculture concept began to pop. So in the countryside, farmers spontaneously run the trend of the $\mathrm{B} \& \mathrm{~B}$, providing people with room and board to play [3].

Early Japanese B\&B is located in the mountains of odd places, due to sinister terrain, few lodging facilities, some adventure and sports enthusiasts will be rented residential temporary residence, these houses became the prototype of the Japanese B\&B. With the odd risk of the progressive development of tourist destinations, clients from sports enthusiasts into tourists, Japan, also from the residential guesthouse rental into a family hotel. In the 1950s, Japan's economy took off and the $\mathrm{B} \& \mathrm{~B}$ grew rapidly in the island of Japan.

In the mainland of China, the development of the hostel started late. In the early 1990s, like the Taiwan region, it was only supplemented by accommodation. The main function was to take care of accommodation and catering. The beginning of this century, the location of residential concern, the main investment to "outside the village" operators and investors, personalization, characteristics began to highlight. After 2010, $\mathrm{B} \& \mathrm{~B}$ into the fine, concerned about the humanities, into the local culture, more diverse investment patterns, shift to cluster-style development. 


\section{THE PROBLEMS EXISTING IN THE DESIGN AND CONSTRUCTION OF THE B\&B IN CHINA}

Data show that China's bed and breakfast is $10 \%-20 \%$ growth rate, the market is huge. As of June 2015, mainland China more than 40,000 bed and breakfast, the market size reached 11.2 billion

However, behind the upsurge in the market, all over the country blindly to build a residential market to seize the market, [4] leading to mixed $\mathrm{B} \& \mathrm{~B}$, boutique hotels rarely. The problems behind the upsurge of guest accommodation should arouse our attention and reflection.

\section{A. Improper site selection}

The premise of $\mathrm{B} \& \mathrm{~B}$ design is location, the design of $\mathrm{B} \& \mathrm{~B}$ has a great relationship with the regional economy, natural environment and human history. It can be said that the loss of relying on those the $\mathrm{B} \& \mathrm{~B}$ basically can not survive.

Since the $B \& B$ has a great dependence, then the importance of $\mathrm{B} \& \mathrm{~B}$ location is self-evident. However, overlooking the domestic residential design, not on the regional resources to conduct a comprehensive assessment and comparison, the blind development and construction of residential, leading to the death of a few cases of the project. Long-term in the past, will inevitably result in resource internal friction, local vicious competition, it is difficult to form economies of scale and local brands and local characteristics.

\section{B. Lack of brand awareness}

Taiwan, Japan and other places to do a good bed and breakfast, most of the hostel owner is a local resident itself, to long-term peace of mind living in $\mathrm{B} \& \mathrm{~B}$, the development of $\mathrm{B} \& \mathrm{~B}$. Therefore, they can withstand the slow development of precipitation can accumulate years of accumulated popularity and experience to build the brand.

However, in China, most of the operators for the individual operators, capital to the countryside, and the personal feelings of the dominant position in the early design did not consider the issue of building planning, leading to post-construction and operation difficulties.

\section{DESIGN HOMOGENEITY}

With the vigorous development of the B\&B industry, the homogenization of the design problem is more and more serious, homogeneous competition, follow the trend of imitation of the "thousand shop side" has become a true portrayal of some of the current industry.

As a non-standard accommodation, unlike the standard hotel, the design and construction of the hotel is more randomized and fragmented, which leads to two kinds of phenomena: one is like a hotel operator, and then to improve and imitate, Quality of serious; the other is the operator depends on their own feelings, think of where to build where personal experience caused by none of the above two phenomena will lead to the design of the homogenization of the problem. The reason for this is that operators lack of local culture unique to the guesthouse, the lack of "local flavor", architectural style, interior decoration and so on are very similar, the lack of personalized, characteristic design.

Aiming at the problems in the design of the above mentioned $\mathrm{B} \& \mathrm{~B}$, this paper summarizes the main points and methods of the $\mathrm{B} \& \mathrm{~B}$, and puts forward the design strategy of $\mathrm{B} \& \mathrm{~B}$.

\section{HIGHLIGHT THE CHARACTERISTICS OF THE HOSTEL LOCATION AND THEME PLANNING}

\section{A. Residential site}

Bed and breakfast as a standard hotel with the distinction of non-standard accommodation, its personality, is characterized by its core competitiveness, but the standard hotel, location is still the most important decisive factor in all factors. In the early stages of design, designers need to consider the location of the hostel from three aspects.

\section{1) The natural environment:}

$\mathrm{B} \& \mathrm{~B}$ is a phenomenon of anti-urbanization, so the surrounding natural environment of the hotel is relatively standard hotel surrounding urban environment differences become an important factor in the choice of bed and breakfast.

\section{2) Human environment:}

Including the location of the local customs, historical relics, and Lingshan town. Human environment is the people in the process of residence in the desire for a deeper level of spiritual experience, determines the style of the design of the boutique.

\section{3) Social environment:}

Including the local government to treat the relevant policies of the accommodation industry, the local residents attitude towards outsiders, and the location of infrastructure improvement and so on. These factors will directly restrict the construction, survival and development.

Natural and cultural environment is the connotation of $\mathrm{B} \& \mathrm{~B}$ design. The social environment is the guarantee of $\mathrm{B} \& \mathrm{~B}$ design.

Only three aspects can reach a good level, so as to provide a solid foundation for $\mathrm{B} \& \mathrm{~B}$ construction and operation.

\section{B. Theme planning}

$\mathrm{B} \& \mathrm{~B}$ theme is the design of pre-construction planning content, the development of the theme will help determine the design direction, but also help build the brand, play the brand.

The theme of the hostel planning based on the surrounding resources, and the location of the decision to stay around the hotel can use the resources [5], but also to some extent, the theme of planning to create the conditions for the hostel. For example, relying on the flower garden, flowers can be sweet and warm atmosphere to create a plan; relying on mountain farmland, is to create slow-paced rural life experience.

The theme of residential planning is the use of natural and cultural resources, but also on the life form of the show. 


\section{THE COMBINATION OF MODERN TECHNOLOGY AND} TRADITIONAL TEXTURE OF THE BUILDING DESIGN

Compared with the standard hotel, residential design in the building there is a big difference. Whether it is rebuilt or new, are to better extract the local history and culture of architectural language, remove the homogenization, to show the personality and characteristics of $\mathrm{B} \& \mathrm{~B}$. For the basic contradictions and problems in the design of the $\mathrm{B} \& \mathrm{~B}$ architecture, this article takes the boutique hotel Cloud House as an example to summarize the concrete treatment method and the architectural design strategy. Cloud House is located in Guangxi Xingping, hidden in the Lijiang River between green water, is from the village nine abandoned farmhouse transformation [6].

\section{A. Traditional crafts and modern materials}

In residential design, the relationship between traditional materials, processes and modern technology is of paramount importance.

Cloud House the entrance of the use of steel sun panels, full of fashion sense; building is the use of local stone, by the local villagers to repair and build the external walls.

Cloud House windows are all made of primary aluminum, contrast with the external walls, highlighting the modern. (Figure 1) traditional materials, technology and modern design complement each other to become a bright spot in the design of $\mathrm{B} \& \mathrm{~B}$.

\section{B. Traditional space and modern facilities}

In the residential design, the need to cleverly solve the traditional interior space and the relationship between modern facilities. Based on the addition of toilets and fire-fighting facilities, the designer replaces the staircase with the bamboo staircase and uses the space around the staircase to set up the bar. Instead of the wood, the physical wall can separate the interior space and sound insulation. Furniture configuration, the smaller the traditional interior space, the pursuit of simplicity in order to maximize the design of the activities of people to increase space. (Figure 2) Design of the traditional interior space appropriate transformation, can make it fully compatible with modern facilities, to ensure that people comfort and safety purposes.

\section{Traditional structure and modern function}

In the structural design, to maintain the original wooden structure, rammed earth walls, green tile roof and roof tiles remain unchanged, as far as possible to keep people old building architectural memory. In the adobe wall, based on the load-bearing wall to increase the light steel gypsum board, strengthening the old room wall, increase its stability. At the same time in order to meet the accommodation requirements, the use of the construction process in the recovery of adobe bricks on the original building as a whole heightened.

In the facade treatment, the main facade of the old house remains the same, the windows of the secondary facade are expanded and the windows are added in the side walls for better lighting and ventilation. For the roof of the shingle, the designer to maintain the original position and the number of cases to increase its size, increase the sense of indoor permeability and light projection to bring beauty. (Figure 3)

In the spatial layout, pay attention to the sharing of indoor public space and the smooth flow line, retaining the middle of the two-story high-ceiling space as a shared living room, on both sides as the layout of the room.

In the material selection, the style to natural, pure, with solid wood, cement, steel and other raw materials, and the original adobe wall to form a unified sense of heavy.

$\mathrm{B} \& \mathrm{~B}$ architectural design is based on local materials on the basis of the building to do the necessary repair, to maximize the preservation of the building's original cultural memory; do the appropriate changes, the maximum possible to meet the needs of modern accommodation.

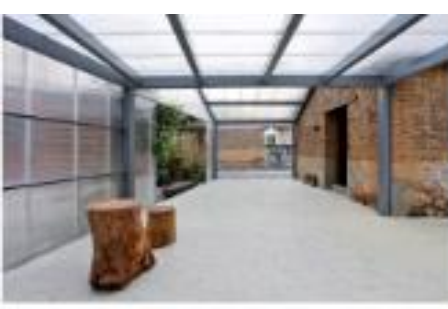

Fig. 1 Cloud House entrance

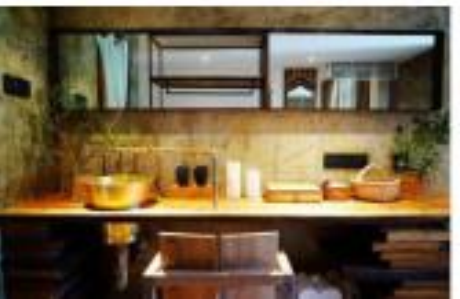

Fig. 5 Yue Ting Nan room

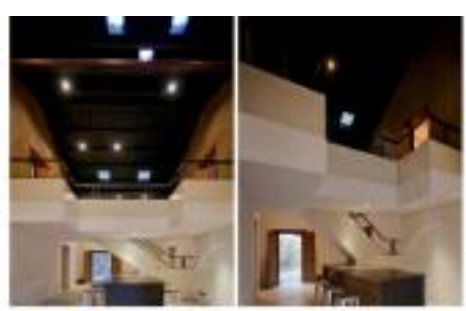

Fig. 2 Cloud House interior space

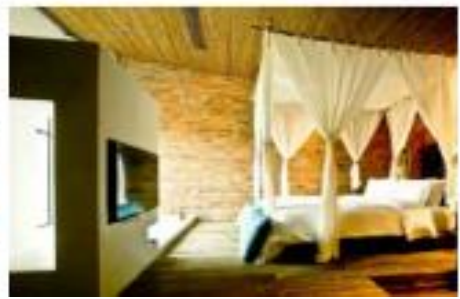

Fig. 6 Yue Ting Nan room rooms

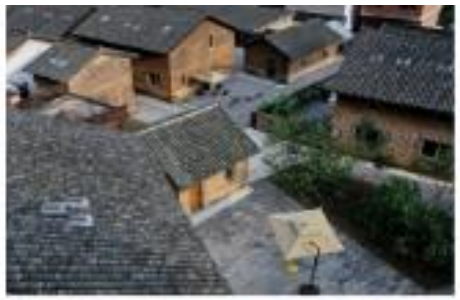

Fig. 3 Cloud House building

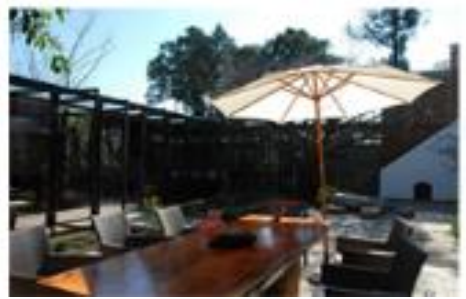

Fig. 7 Air Garden

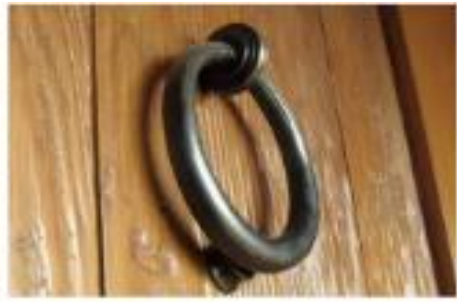

Fig. 4 Yue Ting Nan room copper knock

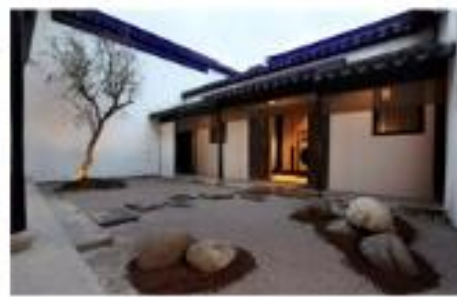

Fig. 8 Hidden House with 


\section{THE MODERN LIFE AND THE TRADITIONAL SPIRIT OF THE DETAILS OF THE DESIGN}

\section{A. Rooms with historical memory}

Like the standard hotel, the rooms are also the most important functional unit of the guest house, which is a great place to experience the bed and breakfast. The details of the room design show the refinement of accommodation and humanization, is a boutique to go the only way. The details of the rooms are everywhere, from the room door or even the use of bathroom, etc., these details are the guests can personally feel. In this paper, fine homes, Yue Ting Nan homes, for example, summed up the details of the room to deal with specific practices and strategies. Yue Ting Nan is located in Zhejiang Yongjia, green mountains and between, is disabled by the transformation of rural sanatorium [7].

Yue Ting Nan homes to "return to the garden home" as the theme, intended to make the guests in order to the door when the door can remember the memory of the old door, the room is using the old copper knock; (Figure 4) bathroom (Figure 5) partition with ordinary red brick piling, an increase of the heavy feeling of the room, cannot help but think of a child when the village is located in the village of the village, Of the "soil house." (Figure 6)

Room details are designed around the theme of the hostel, the expression of the designers of local culture and understanding.

From the guest room details, guests can visually feel the difference between a bed and breakfast and a standard hotel and the difference between a bed and breakfast.

\section{B. Contains the original flavor of the courtyard}

Garden construction involving plants and soft and hard equipment, landscape sketches and lighting, etc., designed to increase the viewing of the $\mathrm{B} \& \mathrm{~B}$, contrast $\mathrm{B} \& \mathrm{~B}$ cultural atmosphere [8]. The author takes boutique hotel air garden and Yinlu same courtyard as an example to summarize its characteristics in courtyard construction.

Air Garden is located in Dali, Yunnan, is located at the foot of Cangshan, is a disrepair of the old house from the transformation. Due to the low building density, the air garden's garden space is very spacious. In the courtyard side, retaining the original old trees, placed under the tree stone tables and chairs, is particularly natural and friendly; the other side, a long wooden table and a combination of knitting chairs to facilitate the exchange between the guests. The south side of the courtyard for the pool, carp play in the pool, to the quiet courtyard adds a bit of vitality. The air garden courtyard to create a similar farmhouse style, old trees, pools, tables and chairs, etc. elements here complement each other to create a relaxed atmosphere. (Figure 7)

Hidden in the same house with the other homes in Suzhou Wujiang, immersed in the old town with the antique, is repaired by the Republic of Pang's home repair. Different from the garden of the air garden, hidden in the same house with the other homes pay more attention to creating a water culture of the ancient house atmosphere. Courtyard is located between the front and rear rooms, due to the compact layout of the building, the space is relatively small. Drawing from Japan's dry landscape of the landscape to create a way, white sand, stacked stone, trees group King, creating a quiet and serene landscape atmosphere. In this atmosphere, the guests can temporarily forget the troubles of life [9], physical and mental well-being rest. (Figure 8)

Different types of accommodation, courtyard to create the atmosphere and the way is different, but there are some commonalities. The courtyard of the guesthouse builds the attentiveness, contrasts the outer beauty of the guesthouse; Explores culture, expresses the cultural connotation of the guesthouse; seek interesting, strengthen the attraction of the hostel and guest experience.

\section{CONCLUSION}

As a non-standard accommodation, the architectural and decorative design of the $\mathrm{B} \& \mathrm{~B}$ is challenging. Because it is not just a place to live, but also people experience the traditional life and spiritual habitat Harbor.

On the basis of this, a feasible design strategy is put forward. Through the combination of modern technology and traditional texture, the design path and method of modern life and traditional spirit blend, provide thought and reference for the design of $\mathrm{B} \& \mathrm{~B}$, guide the villain to rational and characteristic sustainable development.

\section{ACKNOWLEDGMENT}

First of all, thanks to my tutor, Professor Chen Ming. During the three years of his career, he had a profound influence on his attitude towards learning, innovative design thinking, rich design experience and professional knowledge. I hope this paper is not to live up to three years of training and expectations of my qualified answer sheet. Once again express my sincere thanks to my advisor.

Secondly, I'd thank my classmates for giving me encouragement in the investigation period and all the fellow roommates for care and help during my postgraduate life.

In the end, I would like to thank my parents who have stand behind me, to give me the spirit of encouragement and care in life.

Tao Renzhi: Wuhan University of Technology, Master of Civil Engineering and Architecture,

Chen Ming: Wuhan University of Technology,

Associate professor of Civil Engineering and Architecture.

\section{REFERENCES}

[1] Zhai Jian, etc.: "boutique rural residential ecosystem construction study" [J], "Architecture and Culture", 2016.8. (In Chinese)

[2] Zhang Lei. "Contemporary native - Yun Xi Dai Jiashan native art hote She home renovation" [J], "Architecture", 2016 (3). (In Chinese)

[3] Liu Shuhong: "Taiwan's characteristics, space and form" [D], Xiamen: Xiamen University, 2009. (In Chinese) 
[4] Zhang Xin Ran: "Hainan five-star coastal resort hotel standard room design" [J], "Architecture", 2013.5. (In Chinese)

[5] Pang Daijun, etc.: "painting rural courtyard garden landscape design to create" [J], "Garden", 2016.6. (In Chinese)

[6] Qi Shan Shan. "The Beauty of Bed and breakfast " [M]. Guangxi: Guangxi Normal University Press, 2016. (In Chinese)
[7] Phoenix Space Tianjin. "Travel to China: find the most beautiful B \& B" [M]. Jiangsu: Jiangsu Science and Technology Press, 2013. (In Chinese)

[8] Zhao Yuanhong. "Chen Sang Bed and Breakfast" [J], "Architecture", 2014 (3). (In Chinese)

[9] Monica Taylor. Start and Run a Profitable Bed and Breakfast [M]. North Vancouver: Self-Counsel Press, 1984 